\title{
( Workplace Safety: A Necessity or a Luxury in aße the Micro, Small and Medium Enterprises of Bangladesh?
}

\section{Mohammed Nafeez Al Amin}

Freelance Researcher and Musician, Dhaka, BANGLADESH

*E-mail for correspondence: nafeezalamin@gmail.com

Received: Oct 23, 2015;

Accepted: Nov 24, 2015;

Published: Feb 28, 2016

Source of Support: Nil

No Conflict of Interest: Declared

\begin{abstract}
Following the deadliest accidental structural failure in modern human history, Bangladesh Government has been getting external pressure to amend and properly implement its "Workplace Safety Laws". Garment factories like the ones in Rana Plaza (the collapsed building in Savar) are large organizations. Along with the large companies, there are a significant number of micro, small and medium-sized enterprises in Bangladesh which are employing more than 31 million people. Obviously, workplace safety should be a matter of concern for their employers, or is it? Why are they reluctant about it? What is being done to ensure safety? Are they getting pressures or motivated by externalities? Safety measures if taken, is it enough? What else can be done to improve workplace safety? The purpose of this research paper is to find out and analyze the answers to the above questions concerning workplace safety in the MSMEs of Bangladesh. A blend of secondary sources and primary sources (survey amongst a significant number of owners of various MSMEs and observation of a few organizations) of data were used from which both quantitative and qualitative analyses were carried out for the purpose of exploring the unknown. The results show a rather reluctant approach by the owners regarding this issue. However, it was also found that the government has taken a lot of initiatives to minimize workplace safety hazards and is on the verge of implementing them. Thus, a few alternatives that involve lobbying and use of marketing activities to create greater awareness were recommended.
\end{abstract}

Keywords: Micro, small and medium enterprise, workplace safety, Bangladesh Government

JEL Classifications Code: J81, J88

\section{INTRODUCTION}

Bangladesh has been consistently maintaining a GDP of around $5 \%$ over the past decade. A big chunk of this GDP was generated by the ever so efficient Ready Made Garment sector of the country that alone was responsible for $80 \%$ of the exports (BBS, 2010). The achievement of this sector was mainly due to the cost of production being lower than its competing countries. However, this low cost of production in the recent past was often seen coming at a cost. On the 24th of April 2013, the whole world had witnessed what is known as 'The Deadliest Accidental Structure Failure in modern human history,' the collapse of Rana Plaza, which involved dissolution of 3 garment factories and tragic losses of around 1200 lives. An incident similar to what had happened in April 2013 is not the first of its kind in Bangladesh. Fire in Tajreen Fashion which happened in November 2012 and Smart Garments that took place in January 2013 are both prime examples of not meeting the minimum fire safety standards.
It only happened due to the negligence of the factory owners to comply with the workplace health and safety regulations. Since the incident at Savar, the Government started to take actions against the factory owners and inspector-level officers by filing criminal cases against the liable personnel, arresting management level officers and suspending some of the regional factory inspectors. These actions are rather reactive and proved ineffective in the past due to bureaucratic hassles and existence of high level of corruption. However, it is also worth mentioning that the Government has started taking proactive measures to reduce the number of casualties caused by occupational/workplace hazards in the Ready Made Garment Factories in and around the major cities of the country (Ministry of Labor, 2013).

In the recent past, a handful of a number of papers was published on workplace safety or occupational safety in the garments sector of Bangladesh. However, a very little amount of work was done on the workplace safety of micro enterprises of Bangladesh which comprises over 95 
percent of the industrial units and generates a significant amount of employment in the country (Zaman \& Islam, 2011). Therefore, it is very important that we try to understand what these micro small and medium entrepreneurs think about workplace safety and how they are complying. Thus, this journal article talks about the workplace safety in the micro enterprises of Bangladesh.

Against the background of this research, the purpose is to answer the research questions: "What is the current status of workplace safety in the micro, small and medium enterprises of Bangladesh?" In particular this research has three objectives:

- To find out whether workplace safety is a matter of importance to the micro, small and medium entrepreneurs of Bangladesh;

- To find out if entrepreneurs take initiatives to prevent hazardous conditions and injuries; and

- To find out whether the government or any external agency is providing motivation to the entrepreneurs for abiding by the workplace health and safety regulations.

Rest of the article is structured as follows: The first part will consist of reviews of a number of current literatures on the current status of SMEs, workplace safety in the RMG and other manufacturing sectors of Bangladesh, and Government initiatives on workplace safety, etc. This is followed by a description of research methods and procedures, after which the results and the findings are discussed. Finally, the paper concludes with a summary of findings, limitations, and recommendations for further research.

\section{LITERATURE REVIEW}

\section{Workplace safety in the RMG sector}

Many researchers have investigated the working conditions of the RMG sector in the past. Ahamed (2013) in his report writes, "the working conditions in the RMG sector are below standard and do not meet the ILO standards." He also unleashed some of the reasons as to why the standards are not met. The Absence of trade unions, informal recruitment, irregular payment, sudden termination, wage discrimination and abusing child labor are some of the pressing issues that Ahamed (2013) had mentioned in the report along with workplace accidents occurring due to infrastructural failure, etc.

The ILO policies and Codes of Conduct on working condition are often violated by the RMG sector (Qudus \& Rashid, 2000). Bansari (2010) talked about recruitment policy being highly informal and compared it to Western standards. Bansari's report also talks about the lack of formal contracts during employment that leads workers to fear losing their jobs and eventually continuing in unsatisfactory employment. Another report by Kumar (2006) mentioned that the RMG workers are treated like slaves, and they are exploited to increase owner's profit countering the international competition.

Not much attention is given to employee density, evidence of which was acquired by P. Majumder. Majumder (1998) highlighted the fact that the workplaces are often overcrowded, with limited workspace, which is the reason occupational hazards happen such as musculoskeletal disorders and contagious diseases. He also stressed that the lack of labor standards monitoring system, ineffective building codes, poor enforcement, outdated labor laws and lack of awareness of labor rights among workers are also the causes of injuries, fatalities, disablement, and death from fire and building collapses.

\section{Workplace safety in other industries}

All these reports add up to the fact that, workplace safety is considered a luxury for the employees of RMG sector. But, there are other sectors as well where workers are facing safety issues. Tazreen \& Sabet (2013) had details and critics of the most recent RMG sector tragedies and at the same time had their inputs on the workplace safety issues of other industries as well. In the ship breaking industry, workers are exposed to chemicals, machinery, fire, ropes, and chains, etc. without proper protective gear. Due to the lack of compliance by the ship breaking companies, the Supreme Court placed a ban on all ship breaking in 2009.However, due to improvement in working conditions the ban was lifted in 2011.Tazreen\&Sabet (2013) also mentioned about the workplace safety issues of leather industry and construction industry where situations similar to RMG sector were witnessed.

As seen above, a lot of researchers have investigated workplace safety in Bangladesh, and most of the work was done from the context of large enterprises, which left a gap in the market providing opportunities for research on micro, small and medium enterprises. But which enterprises are termed as micro, small and medium?

\section{Micro Small and Medium Enterprises}

According to a report by International Finance Corporation (Kushnir, 2006), the industrial policy of Bangladesh defines medium enterprises as consisting of $25-100$ employees and small enterprises as consisting of less than 25 employees. However, it did not specify what a micro enterprise was and had other variables such as the value of fixed assets attached with the criterion of the enterprises. Moazzem (2011) and Helal \& Zaman (2011) did use all the three terms micro, small and medium while defining and classifying enterprises. They have used micro as units with $0-9$ employees, small units as $10-49$ employees and medium units as $50-99$ employees. These measures will be used in this article as they are up to date and will create less complexity in understanding. Both the above mentioned reports on SME of Bangladesh emphasized on the progress of the companies and their contribution to the overall economy of the country. 
A lot of the researches were based on finding the status of SMEs in Bangladesh. Ahmed (2004), Ahmed \& Chowdhury (2009), and Helal \& Zaman (2011) published overviews on the current status of the small and medium enterprises on 2004, 2009 and 2011 respectively. They have highlighted the SMEs growth, their contribution to the economy, their constraints, skills of workers and owners, and government policies towards SMEs, etc. However, there researches lacked information on workplace safety of the workers.

A lot of other policy papers and newspaper articles were studied which emphasized on the problems of workplace safety in the RMG sector and provided solutions to the problems. These will be discussed later in the recommendations section. United Nations (UN) Workplace Safety Act 2006 elaborated the standards to be followed by every enterprise. This was later adopted by the Bangladesh Ministry of Labor as they incorporated them in the Gazette of 2006. For this research, the UN Workplace Safety Act of 2006 was used as a mold to formulate the questionnaire survey. All the details about the survey techniques and data collection procedure, etc. will be discussed in details in the next section.

Based on the literature review and current workplace safety scenario of Bangladesh the following working hypotheses (assumptions made before exploring the subject area) were formulated:

$\mathrm{H}_{1}$ (null): Workplace safety is not a matter of importance to the micro, small and medium entrepreneurs of Bangladesh

$\mathrm{H}_{1}$ (alternative): Workplace safety is a matter of importance to the micro, small and medium entrepreneurs of Bangladesh

$\mathrm{H}_{2}$ (null): Micro, small and medium entrepreneurs do not take initiatives to prevent hazardous conditions and injuries

$\mathrm{H}_{2}$ (alternative): Micro, small and medium entrepreneurs take initiatives to prevent hazardous conditions and injuries; and

$\mathrm{H}_{3}$ (null): The government or any external agencies do not take enough initiatives so that the entrepreneurs abide by the workplace health and safety regulations

$\mathrm{H}_{3}$ (alternative): The government or any external agencies take enough initiatives so that the entrepreneurs abide by the workplace health and safety regulations

\section{ANALYSIS AND FINDINGS}

\section{Frequencies}

Statistical Package for Social Sciences (SPSS) was used to perform the data analysis. The first question was about the number of employees the entrepreneurs employed. The purpose of this question was to find the types of enterprises surveyed. The following table shows the findings:

Table 01: Number of Employees

\begin{tabular}{|ll|r|r|r|r|}
\hline & Frequency & Percent & Valid Percent & Cumulative Percent \\
\hline Valid & $0-9$ & 279 & 84.0 & 84.0 & 84.0 \\
& 27 & 8.1 & 8.1 & 92.2 \\
& $23-49$ & 23 & 6.9 & 6.9 & 99.1 \\
$50-99$ & 3 & .9 & .9 & 100.0 \\
more than 100 & 332 & 100.0 & 100.0 & \\
Total & & & \\
\hline
\end{tabular}

As we can see the total number of respondent enterprises were 332 of which 279 were micro units representing $84 \%$ of the total sample. Around $8 \%$ were small units and $6.9 \%$ were medium.
Five questions were made responsible to find out whether workplace safety is important to the survey participants. Following are the frequency charts generated from the answers to those questions:

Table 02: Effort to furnish to reduce hazard

\begin{tabular}{|ll|r|r|r|r|}
\hline & Frequency & Percent & Valid Percent & $\begin{array}{c}\text { Cumulative } \\
\text { Percent }\end{array}$ \\
\hline Valid & Neutral & 35 & 10.5 & 10.5 & 10.5 \\
& Agree & 248 & 74.7 & 74.7 & 85.2 \\
& Strongly agree & 49 & 14.8 & 14.8 & 100.0 \\
& Total & 332 & 100.0 & 100.0 & \\
\hline
\end{tabular}

The Majority of the respondents agreed that they put sufficient effort to furnish the premises to reduce hazardous conditions that could cause death or seriously harm employees. There were no disagreements with the question. However, $10.5 \%$ of the responses were neutral. 
Table 03: Inform employees about danger

\begin{tabular}{|ll|r|r|r|r|}
\hline & Frequency & Percent & Valid Percent & Cumulative Percent \\
\hline Valid & Disagree & 18 & 5.4 & 5.4 & 5.4 \\
& Neutral & 22 & 6.6 & 6.6 & 12.0 \\
Agree & 284 & 85.5 & 85.5 & 97.6 \\
Strongly Agree & 8 & 2.4 & 2.4 & 100.0 \\
Total & 332 & 100.0 & 100.0 & \\
\hline
\end{tabular}

When asked about informing their employees about potential hazards, most of the responses were positive. A total of 284 respondents agreed to the question. Unfortunately, 5.4\% of the entrepreneurs disagreed to the question.

Table 04: Ensure employees do not engage in inappropriate activities

\begin{tabular}{|ll|r|r|r|r|}
\hline & Frequency & Percent & Valid Percent & Cumulative Percent \\
\hline Valid & Strongly disagree & 1 & .3 & .3 & .3 \\
Disagree & 29 & 8.7 & 8.7 & 9.0 \\
Neutral & 25 & 7.5 & 7.5 & 16.6 \\
Agree & 259 & 78.0 & 78.0 & 94.6 \\
Strongly Agree & 18 & 5.4 & 5.4 & 100.0 \\
Total & 332 & 100.0 & 100.0 & \\
\hline
\end{tabular}

A total of 259 participants said that they agreed about ensuring that the employees do not engage in inappropriate activities in the workplace. Although most of the answers were positive, about $9 \%$ responses of this question were "disagree" or "strongly disagree".

Table 05: Maintain to avoid danger

\begin{tabular}{|ll|r|r|r|r|}
\hline & Frequency & Percent & Valid Percent & Cumulative Percent \\
\hline Valid & Disagree & 22 & 6.6 & 6.6 & 6.6 \\
& Neutral & 29 & 8.7 & 8.7 & 15.4 \\
Agree & 264 & 79.5 & 79.5 & 94.9 \\
Strongly agree & 17 & 5.1 & 5.1 & 100.0 \\
Total & 332 & 100.0 & 100.0 & \\
\hline
\end{tabular}

264 respondents agree that they regularly get the maintenance done for the equipment inside the premises to avoid danger. 17 employees strongly agreed to the questions with 29 and 22 respondents saying "neutral" and "disagree" respectively.

Table 06: Ensure that the tools and machines can perform safely

\begin{tabular}{|ll|r|r|r|r|}
\hline & Frequency & Percent & Valid Percent & Cumulative Percent \\
\hline Valid Strongly disagree & 1 & .3 & .3 & .3 \\
Disagree & 3 & .9 & .9 & 1.2 \\
Neutral & 25 & 7.5 & 7.5 & 8.7 \\
Agree & 259 & 78.0 & 78.0 & 86.7 \\
Strongly agree & 44 & 13.3 & 13.3 & 100.0 \\
Total & 332 & 100.0 & 100.0 & \\
\hline
\end{tabular}


When asked about whether the entrepreneurs ensure that the machineries and tools are able to perform safely, replies were mostly for "agree" and "strongly agree". Negligible amount of respondents came up disagreeing with the questions. Twenty-five of the responses were "neutral".

The following table with the 5 columns will help us find out whether the micro, small and medium entrepreneurs find it important to ensure workplace safety. The means and the standard deviations corresponding to the questions are mentioned which were generated after analyzing the five questions. The means comparatively closer to 5.00than 1.00 shows the tendency of the answers going towards "strongly agree" and vice versa.

\section{Table 07: Importance of Workplace Safety}

\begin{tabular}{|c|c|c|c|c|c|c|}
\hline & & $\begin{array}{l}\text { Effort to furnish to } \\
\text { reduce hazard }\end{array}$ & $\begin{array}{l}\text { Inform } \\
\text { employees } \\
\text { about danger }\end{array}$ & $\begin{array}{c}\text { Ensure employees do } \\
\text { not engage in } \\
\text { inappropriate activities }\end{array}$ & $\begin{array}{l}\text { Maintain to } \\
\text { avoid danger }\end{array}$ & $\begin{array}{l}\text { Ensure that the } \\
\text { tools and } \\
\text { machines can } \\
\text { perform safely }\end{array}$ \\
\hline \multirow[t]{2}{*}{$\mathrm{N}$} & Valid & 332 & 332 & 332 & 332 & 332 \\
\hline & Missing & 0 & 0 & 0 & 0 & 0 \\
\hline \multicolumn{2}{|c|}{ Mean } & 4.04 & 3.85 & 3.80 & 3.83 & 4.03 \\
\hline \multicolumn{2}{|c|}{ Std. Deviation } & .502 & .534 & .682 & .613 & .521 \\
\hline
\end{tabular}

Test for Hypothesis 1: Findings from analyzing the frequencies and the above chart we can say that most of the respondents agreed that they give importance to workplace safety. The means for the 5 question were around 4.00 and standard deviations which were not alarming. Therefore, it can be seen that the micro, small and medium entrepreneurs are giving importance to workplace safety at their premises. In the next set of questions, the entrepreneurs were asked if they train up their employees regarding workplace safety. Most of the answers showed that they do. However, $28 \%$ of the respondents disagreed and said that they do not train their employees.

Table 08: Know and encourage about PPE

\begin{tabular}{|ll|r|r|r|r|}
\hline & Frequency & Percent & Valid Percent & Cumulative Percent \\
\hline Valid & Strongly disagree & 13 & 3.9 & 3.9 & 3.9 \\
& 260 & 78.3 & 78.3 & 82.2 \\
Disagree & 21 & 6.3 & 6.3 & 88.6 \\
Neutral & 34 & 10.2 & 10.2 & 98.8 \\
Agree & 4 & 1.2 & 1.2 & 100.0 \\
Strongly Agree & 332 & 100.0 & 100.0 & \\
Total & &
\end{tabular}

The entrepreneurs were then asked if they have sufficient knowledge on Personal Protective Equipments (PPE) and encourage their employees to use of PPE. Most of the respondents disagreed and around $11 \%$ agreed. A total of 266 participants agreed to the fact that they make sure regular inspection of workplaces and processes are done.
The majority of the respondents agreed that they do not permit employees inside the premises if danger is perceived. Similar picture was also seen when the entrepreneurs were faced with the question regarding ensuring of adequate escape route during hazards.

Table 10: Prevention of Workplace Hazards

\begin{tabular}{|l|r|r|r|r|r|}
\hline & $\begin{array}{c}\text { Train up employees } \\
\text { regarding workplace } \\
\text { safety }\end{array}$ & $\begin{array}{c}\text { Know and } \\
\text { encourage } \\
\text { about PPE }\end{array}$ & $\begin{array}{c}\text { Regular } \\
\text { inspection of } \\
\text { workplaces and } \\
\text { processes }\end{array}$ & $\begin{array}{c}\text { Don't permit } \\
\text { employees in if } \\
\text { perceived } \\
\text { danger }\end{array}$ & $\begin{array}{c}\text { Ensure } \\
\text { adequate escape } \\
\text { route while } \\
\text { danger }\end{array}$ \\
\hline $\mathrm{N} \quad$ Valid & 332 & 332 & 332 & 332 & 332 \\
Mean & 0 & 0 & 0 & 0 \\
Std. Deviation & 3.37 & 2.27 & 3.78 & 3.92 \\
\hline
\end{tabular}


Test for Hypothesis 2: Findings from analyzing the frequencies we can say that most of the respondents agreed that they take necessary steps to prevent workplace hazards. The means for the next five questions were around 3.00 to 4.00except for the question on PPE which came out to be 2.27. The standard deviations of these questions came out higher than the first five questions which was a matter of concern. Therefore, we can say that the micro, small and medium entrepreneurs are giving full effort for the prevention of workplace hazards.

The next two questions were regarding the frequency of visits by the health and safety inspectors to their premises and regarding any government or external agency incentives for ensuring health and safety.

Table 11: How often do they get visits from H\&S inspectors?

\begin{tabular}{|ll|r|r|r|r|}
\hline & Frequency & Percent & Valid Percent & Cumulative Percent \\
\hline Valid & Once every fortnight & 1 & .3 & .3 & .3 \\
Once every quarter & 4 & 1.2 & 1.2 & 1.5 \\
Once every six months & 18 & 5.4 & 5.4 & 6.9 \\
Once a year & 124 & 37.3 & 37.3 & 44.3 \\
Once every 5 - 10 years & 108 & 32.5 & 32.5 & 76.8 \\
Never & 77 & 23.2 & 23.2 & 100.0 \\
Total & 332 & 100.0 & 100.0 & \\
\hline
\end{tabular}

When faced with the question of how often entrepreneurs get visits from health and safety inspectors, majority of the answers were either once a year or once every $5-10$ years. Some of the respondents answered "never".

\section{Government Initiatives}

\begin{tabular}{|l|r|r|}
\hline & $\begin{array}{c}\text { How often do you get visit from } \\
\text { H\&S inspectors? }\end{array}$ & $\begin{array}{c}\text { Government gives incentives } \\
\text { for ensuring H\&S }\end{array}$ \\
\hline $\mathrm{N} \quad$ Valid & 332 & 332 \\
Missing & 0 & 0 \\
Mean & 6.70 & 4.19 \\
Std. Deviation & .958 & .495 \\
\hline
\end{tabular}

The above chart shows the mean value 4.19 that signifies that most of the respondents agreed about government providing them incentives for ensuring health and safety. Even with the value of standard deviation being 0.495 , the inference remains the same.

Although the government provides incentives, inspections are done irregularly and rarely. Thus, government initiatives are still questionable.

\section{Discussion}

The study investigated the current status of workplace safety conditions in micro, small and medium enterprises by surveying 332 MSME owners inside Dhaka City. To my knowledge, it is the first study that focused on workplace safety in the MSMEs of Bangladesh.

\section{Summary of Findings}

From this study we have seen that the micro, small and medium enterprise owners do give importance to workplace safety. However, it was also found that these owners are not taking enough preventive measures to avoid the rising of workplace hazards that may lead to employee injuries or at times death. Similarly, when the observation was being conducted, it was seen that preventive measures were not being taken seriously by certain employers and sometimes not even being acknowledged.

Tazreen \& Sabet (2013) reported the ship breaking industry went through a period of a ban, due to their lack of compliance with the workplace safety laws. The ship breaking companies could continue their work when a sense of importance on workplace safety was seen. After the Rana Plaza incident, we have seen companies in the RMG sector taking the safety of employees seriously. People in other sectors have become aware and are concerned about the negative consequences of failure to comply with workplace safety. Criminal cases were filed against the building and the garment factory owners of Rana Plaza (Bangladesh Labor Ministry, 2013). The cases are currently under trial. Hence, most of the respondents agreed with workplace safety being important.

When it came to the question of what steps they have taken to prevent hazards, not so enthusiastic answers were received. Mixed reactions were mostly witnessed in 
the replies. Reasons can be deduced as lack of knowledge and lack of finance (Haque et al. 2003). For instance, very few respondents knew about personal protective equipment or cannot encourage their employees to use them because of the expenses. An employee of a five member welding shop was given a $4^{\prime \prime} X 2$ " black tinted piece of glass to get the entire welding job done. When asked informally about why the owner is not giving him safety goggles, suits, and gloves, etc. the owner replied that the employee needs to be more careful about his well-being and the PPEs are expensive. Thus, workplace safety is still a luxury.

According to our findings the government may not have done enough to stimulate workplace safety inspections but it has certainly taken a lot of initiatives recently. Below are some of the initiatives taken by the government in recent times:

- Amendment of Labor Law 2006 which would allow workers' right to form trade union easier, ensure workplace safety, provision for compulsory insurance system and enhancement of gratuity, etc. (Ministry of Labor, 2013)

- 23 special inspection teams formed to inspect the RMG factories.

- $\quad$ Reduced tax on fire fighting equipments (Ministry of Labor, 2013)

\section{Limitations and Recommendations}

Some limitations might be related to the collection of data and interpretation of results. The first limitation might be the omission of important variables. For example, employee work load, working hours, remunerations and compensations, and discriminations could have been additional antecedents of workplace safety.

Another potential shortcoming in the study is the respondent's biasness towards what is perceived to be right. For instance, while the survey was being done, a lot of the times respondents seemed nervous and were not liking the fact that they were being questioned. To be exact, questions they may lead to them spending money on something that they had not considered or do not want to consider. Some of them even suspected that I am a representative of the ruling party and answers against the government may have adverse effects on them.

The third limitation was with selection of samples. The survey was Dhaka-based, a place where standards of living are much higher compared to the suburban areas. The research outcome might have been different if that was the case. However, the biggest limitation is literacy of people. The literacy rate of Bangladesh is around 55\% (Bangladesh Bureau of Statistics, 2010) but not much of this percentage is educated enough to understand the significance of human life or well-being.

Therefore, taking all the problems into consideration the following points can be recommended:
- Behavioral study of the entrepreneurs on workplace safety

- Inclusion of more variables in the research of this topic

- Sampling as close to the demographics of Bangladesh as possible

- Government may use marketing techniques to promote or make people aware about the workplace safety and labor laws that are in place and take necessary actions to increase inspection to at least once every six months

- Government may also establish a 24-hour health and safety hotline for increasing knowledge and assistance in health and safety

- International brands may persuade its Bangladeshi supplier to meet the ILO workplace safety standards (Nash, 2013)

Some recommendations were received from the answers of the open-ended questions. They are given below:

- The labor unions or owners' unions may employ area wise inspectors at their own expenses

- Government should take the initiative of training at least one employee of the organization

- The manufacturing plants may be relocated to the industrial areas

\section{REFERENCES}

Ahamed, F. (2013). Improving Social compliance in Bangladesh's Ready-made Garment Industry.

Ahmed, D. M. (2004). The Small and Medium Enterprises (SME) in Bangladesh: An Overview of the Current Status. Dhaka.

Bangladesh Bureau of Statistics. (2011). Bangladesh Literacy Survey 2011. Dhaka: Bangladesh Government.

Bangladesh National Assembly. (2006). Bangladesh Gadget. Dhaka: Bangladesh Government.

Gyekye, S. A. (2005). Workers' Perception of Workplace Safety and Job Satisfaction. International Journal of Occupational Safety and Ergonomics (JOSE), 11 (3), 291 - 302.

Haque, D. A. (2003). Economic Policy Paperon Access to Finance for SMEs: Problems and Remedies. Dhaka: The Dhaka Chamber of Commerce and Industry.

Kashfia, A., \& Chowdhury, T. A. (2009). Performance Evaluation of SMEs of Bangladesh. International Journal of Business and Management , $126-133$.

Kushnir, K. (2006). How Do Economies Define Micro, Small and Medium Enterprises (MSMEs)? Companion Note for the MSME Country Indicators .

Ministry of Industries Government of the People's Republic of Bangladesh. (2005). Policy Strategies for Small $\mathcal{E}$ Medium Enterprises (SME) Development in Bangladesh. Dhaka: Bangladesh Government.

Ministry of Labor. (2013). Steps taken by Government and other Agencies after the incidents at Tajreen Fashions Ltd., Smart Garments and Rana plaza as of 03-07-2013. Dhaka: Bangladesh Government.

Ministry of Labour. (2012). Labor Policy 2012. Bangladesh Gadget (pp. 76455 - 76465). Dhaka: Bangladesh Government.

Moazzem, D. K. (2013). Micro, Small and Medium Enterprises in Bangladesh: Are They Scaling Up? Dhaka: Centre for Policy Dialogue (CPD). 
Nash, J. (2013, August). Will Dueling Standards Improve Worker Safety in Bangladesh? Retrieved September 2013, from Reg Blog: https:/ /www.law.upenn.edu/blogs/regblog/2013/07/16nash-dueling-standards.html

Qudus, M., \& Rashid, S. (2000). Entrepreneurs and Economic Development: the remarkable story of garment exports from Bangladesh. Journal of Bangladesh Studies , 65 - 66.

Sohani, N. Z., Chaklader, M. A., Faruquee, M. H., Bashar, M. A., Yasmin, R., \& Yasmin, N. (2011). PATTERN OF WORKPLACE VIOLENCE AGAINST FEMALE GARMENT
WORKERS IN SELECTED AREAS OF DHAKA CITY. SUB Journal of Public Health .

Tazreen, A., \& Sabet, D. M. (2013, April). Worker Safety in Bangladesh: Looking Beyond Garments. Retrieved August 2013, from University of Liberal Arts Bangladesh: www.ulab.edu.bd/CES/documents/

Zaman, A. K., \& Islam, M. J. (2011). Small and Medium Enterprises Development in Bangladesh: Problems and Prospects . ASA University Review , 145-160.

\section{SocIAL ScIENCE RESEARCH NETWORK \\ 2171 Monroe Avenue, Suite 203, Rochester, NY 14618, USA \\ http://www.ssrn.com/en/}

AJTP Link: http://www.ssrn.com/link/American-Journal-Trade-Policy.html 